\title{
Effect of Lanthanum Doping on the Microstructure Evolution and Intermetallic Compound (IMC) Growth during Thermal Aging of SAC305 Solder Alloy
}

Tabassum Yasmin ${ }^{1 *}$, Muhammad Sadiq ${ }^{1}$ and Muhammad Imran Khan ${ }^{2}$

${ }^{1}$ University of Engineering \& Technology Peshawar, Pakistan

${ }^{2}$ Mari Petroleum Company Ltd, Pakistan

\begin{abstract}
Sn96.5Ag3Cu0.5 (SAC305) is widely used as lead-free solder for surface mount technology (SMT) card assembly and for ball-grid-array (BGA) interconnection in the microelectronic packaging industry as solder balls and pastes. In this study the effects of Lanthanum (La) doping on SAC305 under thermal aging was investigated as function of intermetallic compounds (IMCs) growth and grain size evolution. The morphology of the microstructure was analyzed under Scanning Electron Microscope (SEM) and optical microscope, the elemental distribution was confirmed by Energy Dispersive Spectroscopy (EDS) and phase identification of the crystalline structure formed during thermal aging was confirmed by x-ray diffraction (XRD). It was found that the microstructure of SAC305 solder alloy changes significantly with addition of La. Quantitative analysis of grain size and intermetallic particle size was performed both for undoped and La-doped SAC305 alloys.
\end{abstract}

Keywords: IMCs; Thermal aging; Grain size; Particle; Solder; SAC305

\section{Introduction}

The increasingly environmental concern over the toxicity of lead $(\mathrm{Pb})$ combined with strict environmental regulations around the world have been targeted to eliminate the usage of $\mathrm{Pb}$-bearing solders in electronic assemblies and to adopt lead-free solder alloys [1-5]. The European Union Waste Electrical and Electronic Equipment (WEEE) Directive, published in 2002 and Restriction of Hazardous Substances (RoHS) Directive of European Community, published in 2003 restricted the usage of certain toxic materials including Lead $(\mathrm{Pb})$ in production of electronic devices used in European Union effective on 1 July 2006 [6].

Owing to the enforcement of these directives, all electrical or electronic equipment and devices produced in or imported to EU member countries must meet the lead-free standards except those items that are exempted from the bans. Furthermore, several Japanese electronics manufacturers have successfully created a market differentiation and increased market share based on "green" products that use $\mathrm{Pb}$-free solders and many Japanese companies have brought their lead-free products into the market much earlier than the EU directives' effective dates, including Panasonic in 2001, Sony in 2001: Toshiba in 2000, NEC in 2002, and Hitachi in 2001. In the United States, there are no specific government regulations regarding usage of $\mathrm{Pb}$ solder in electronic consumer products. However, the U.S. Environmental Protection Agency (EPA) has listed lead among the top 17 chemicals that conduce to threat for human health. The IPC (formerly known as the Institute of Interconnecting and Packaging Electrical Circuits) has also developed a roadmap for the lead-free movement in the U.S. [7].

Moreover many U.S. companies, including Motorola, Cisco, and Intel, have also been actively pursuing lead-free products in order to protect their world-wide market shares. Many universities have also been actively funding lead-free related research. Other countries, such as China and South Korea, which are emerging electronic manufacturing bases, have also adopted or are in the process of adopting directives similar to those of the European Union.
This multinational decision has led to vigorous development of alternative solder alloys and the most promising of these falls into the general alloy families of tin-silver $(\mathrm{Sn}-\mathrm{Ag})$ and tin-silver-copper ( $\mathrm{Sn}-\mathrm{Ag}-\mathrm{Cu}$ ). They were first discovered in 1996 by a research group at Ames Laboratory in USA [8]. Various type of $\mathrm{Sn}-\mathrm{Ag}-\mathrm{Cu}$ or SAC alloys have been the proposed by industrial consortiums e.g. In Japan, the Japan Electronic Industry Development Association (JEIDA) has recommended $96.5 \mathrm{wt} \% \mathrm{Sn}-3 \mathrm{wt} \% \mathrm{Ag}-0.5 \mathrm{wt} \% \mathrm{Cu}$ (SAC-305), in the EU, the European Consortium - the Industrial and Materials Technologies Program Brite-Euram, recommended 95.5wt\%Sn3.8wt $\% \mathrm{Ag}-0.7 \mathrm{wt} \% \mathrm{Cu}$ (SAC-387), and in US, NEMI has recommended 95.5wt\%Sn-3.9wt\%Ag-0.6wt\%Cu (SAC-396) for reflow soldering and 99.3Sn-0.7Cu for wave soldering [9].

Among the various lead-free solders SAC-305 alloy has emerged as the most widely accepted to replace $\mathrm{Sn}-\mathrm{Pb}$ solders. It is widely used as lead-free solder for surface mount technology (SMT) card assembly and for ball-grid-array (BGA) interconnection in the microelectronic packaging industry as solder balls and pastes. More than $70 \%$ market for reflowing lead-free solders are in the SAC series. Due to having good mechanical properties, acceptable wetting properties, and suitable melting points, the International Printed Circuit Association has suggested that SAC-305 and SAC-396 will be the most widely used alloys in the future [10-16].

Although SAC-305 alloy is widely used in electronics industry, it has several problems to be solved. One of the core issues pertaining to

*Corresponding author: Tabassum Yasmin, University of Engineering \& Technology Peshawar, Pakistan, Tel: +92 91 9216796; E-mail: tabassum@nwfpuet.edu.pk

Received June 23, 2014; Accepted October 07, 2014; Published October 13, 2014

Citation: Yasmin T, Sadiq M, Khan MI (2014) Effect of Lanthanum Doping on the Microstructure Evolution and Intermetallic Compound (IMC) Growth during Thermal Aging of SAC305 Solder Alloy. J Material Sci Eng 3: 141. doi:10.4172/21690022.1000141

Copyright: (C) 2014 Yasmin T, et al. This is an open-access article distributed under the terms of the Creative Commons Attribution License, which permits unrestricted use, distribution, and reproduction in any medium, provided the original author and source are credited. 
SAC-305 is the formation and growth of large intermetallic compounds (IMCs) in this alloy [17]. IMC are produced as result of the reaction of a molten solder with a conductive metal i.e. $\mathrm{Cu}$. $[18,19]$. Although the presence of thin layer of IMCs between solders and conductor metals is desirable because it results in good metallurgical bonding [19]. However, a thick IMCs layer at the solder/conductor metal interface significantly reduces the reliability of the solder joints because of their inherent brittle nature and their tendency to generate structural defects because physical properties (such as elastic modulus and coefficient of thermal expansion) of IMCs are not compatible with parent metal i.e. SAC alloy $[1,10,19-26]$. IMC have much higher strength than the bulk solder material $[27,28]$. "They are stoichiometric combinations of two or more metal atoms where the atomic fractions of the metals are generally fixed (for example Cu3Sn). This can be contrasted with solid solutions where the atomic fractions can sometimes very as widely as $0-100 \%$. Metals and alloys exhibit metallic bonding between the atoms, whereas IMCs exhibit a more covalent character. This is why IMCs tend to be much harder and have much higher elastic moduli than either of their respective metallic elements i.e. Sn, $\mathrm{Ag} \& \mathrm{Cu}$ " [29].

Prolonged exposure to high thermal environment causes these IMCs to grow [30,31]. Figure 1 shows how thermal aging leads to growth of the IMC layer between SAC305 solder and copper. The operating temperature of many new electronic systems could be as high as $200^{\circ} \mathrm{C}$, for example electronics in oil and gas exploration, avionics, automotive industry, and defense applications typically have more demanding thermal life cycle environments than consumer electronics [32,33]. In oil and gas well drilling nearly $15 \%$ of the wells have bottom hole temperature in the range of $150^{\circ} \mathrm{C}-175^{\circ} \mathrm{C}$ and 2 to $3 \%$ have temperature upto $200^{\circ} \mathrm{C}$ or higher [34]. A typical application of high thermal environmental conditions experienced by electronic system during oil and gas well drilling is running of wireline logging / slickline tools in high temperature wells. Memory gauges which are used for recording of bottom-hole pressure and temperature of oil \& gas well encountered to a temperature range of $150^{\circ} \mathrm{C}-175^{\circ} \mathrm{C}$ with exposure time vary from 30 to 60 hours. Similarly high temperatures are encountered in the electronics used in supersonic aircrafts, military vehicles e.g. battle tanks. These demanding conditions of use, together with the need for greater reliability of all electronic systems motivate further research on the effects of high temperature aging of solder materials [35].

For SAC alloys most often IMC are $\mathrm{Cu}_{6} \mathrm{Sn}_{5} \& \mathrm{Ag}_{3} \mathrm{Sn}$. The IMC $\mathrm{Cu}_{6} \mathrm{Sn}_{5}$ is important due to the large number of lead-free solder joints formed directly to copper. In addition, the $\mathrm{Cu}_{6} \mathrm{Sn}_{5} \mathrm{IMC}$ is a primary feature in the microstructure of SAC305 alloy. During
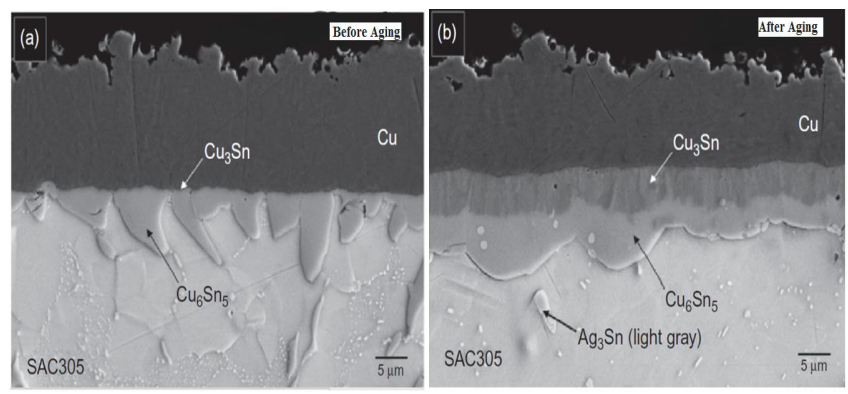

Figure 1: (a) A joint from a ball grid array package made from SAC305 solde with SOP surface finish (b) After aging, the $\mathrm{Cu}_{6} \mathrm{Sn}_{5} \mathrm{IMC}$ layer grew thicker with time and temperature, and a $\mathrm{Cu}_{3} \mathrm{Sn}$ layer formed between the $\mathrm{Cu}_{6} \mathrm{Sn}_{5}$ and $\mathrm{Cu}$ layer (Aging Time $120 \mathrm{hrs} @ 100^{\circ} \mathrm{C}$ ). soldering process, the conductive metal $\mathrm{Cu}$ is rapidly dissolved into a liquid solder until the solder becomes supersaturated with $\mathrm{Cu}$ at the $\mathrm{Cu}$ /liquid solder interface. At the same time the driving force for chemical reaction between $\mathrm{Cu}$ and $\mathrm{Sn}$ promotes the formation of a $\mathrm{Cu}-\mathrm{Sn}$ intermetallic compound, often $\mathrm{Cu}_{6} \mathrm{Sn}_{5}$ phase, by heterogeneous nucleation and growth at the $\mathrm{Cu} /$ liquid interface $[19,36,37]$. These IMCs usually have a scallop-like appearance [38] and change to a plate structure during thermal aging [39]. Thermodynamically, there should also be an intermetallic phase $\mathrm{Cu}_{3} \mathrm{Sn}$ formed between $\mathrm{Cu}$ and $\mathrm{Cu}_{6} \mathrm{Sn}_{5}$ but it is usually very thin making it difficult to detect [19,39-41]. The dominant diffusing element through both the $\mathrm{Cu}_{3} \mathrm{Sn}$ and the $\mathrm{Cu}_{6} \mathrm{Sn}_{5}$ phases is copper [42]. This leads to a depletion of copper at the $\mathrm{Cu}$ $\mathrm{Cu}_{3} \mathrm{Sn}$ interface and in the $\mathrm{Cu}_{3} \mathrm{Sn}$ layer resulting in the formation of Kirkendall voids. Many researchers have observed Kirkendall voids both at the $\mathrm{Cu}-\mathrm{Cu}_{3} \mathrm{Sn}$ interface and within the $\mathrm{Cu}_{3} \mathrm{Sn}$ layer [19,43-47]. Kirkendall voids usually appear in the $\mathrm{Cu}_{3} \mathrm{Sn}$ layer or at the $\mathrm{Cu}_{3} \mathrm{Sn} / \mathrm{Cu}$ interface when exposed to temperatures above $100^{\circ} \mathrm{C}$. The formation of Kirkendall voids greatly increases the chance of failure due to brittle fracture [48]. The size of the voids is about 0.1 to $0.2 \mu \mathrm{m}$. Owing to this small size, they are smeared during mechanical polishing and therefore it is not possible to observe them after polishing [43]. If it shall be possible to observe the Kirkendall voids, the surface needs to be prepared using methods such as Focused Ion Beam (FIB) or sputtering with Ar+ ions. Therefore, Kirkendall voids may be more common than reported [37]. $\mathrm{Ag}_{3} \mathrm{Sn}$ is the other IMC that can form in the matrix of the SAC solders as needle like structure. Large $\mathrm{Ag}_{3} \mathrm{Sn}$ plates is the least desirable phase since it extensively affect the mechanical properties of solder joints $[49,50]$ by producing local plastic deformation [51] and conduce to stress concentration at the interface between the hard $\mathrm{Ag}_{3} \mathrm{Sn}$ particles and soft $\beta$-Sn [52] that results in catastrophic failures of electronic components. They are generally believed to be detrimental in both crack initiation and propagation, and numerous studies have attributed the failure of SAC305 solders to large plate-like $\mathrm{Ag}_{3} \mathrm{Sn}$ IMCs under impact and thermal cycling stimuli $[10,17,53]$. In addition, the formation of large plate like $\mathrm{Ag}_{3} \mathrm{Sn}$ IMCs causes solid dissolution and precipitation hardening, which in turn decreases the matrix strength $[54,55]$. The overall reliability of the solder joint can be greatly affected by the amount and size of $\mathrm{Ag}_{3} \mathrm{Sn}$ IMCs in the microstructure [56]. Since the Cu content in the SAC-305 alloy is very small, the majority of the IMCs formed in SAC305 are Ag3Sn particles.

To cater these problems, the rare earth (RE) elements have been added into the $\mathrm{Sn}-\mathrm{Ag}-\mathrm{Cu}$ based solder. The RE elements has some unique properties that make it have extensive applications in material and metallurgy field. Rare earth elements (RE) have been successfully used in the steel industry [57]. RE are the surface-active agents which greatly affect the metallurgy of materials e.g. refinement of microstructure, purification of materials and metamorphosis of inclusions [58]. They have been regarded as the vitamin of metals, whereby addition of a small quantity of rare earth elements may dramatically change the performance of metals e.g refining the microstructure [57-80]. They can more easily agglomerate at the grain/ dendrite boundary and lower the grain/dendrite boundary energy to stabilize the boundaries and restrain the moving or sliding of the boundaries [25]. Some studies consider that RE elements are adsorbed at the grain/dendrite boundaries of the IMC and alter the relative correlation of the growth velocities between the crystalline directions of the polycrystalline IMC, which decrease the size of the IMC particles and distributes the IMCs more uniformly [81-87]. Several studies [5780] have been conducted to find the effect of RE doping in solder alloys, the RE used generally are La, Ce, Y and Er. These studies demonstrate 
that RE doping can significantly increase the wetting property of solder [14,57-58,64,75-76,81], it can reduce IMCs particle size and their growth on solder/pad interfaces, and thus greatly increase the solder joint reliability [73]. Some researchers have found that the difference in atomic radius between $\mathrm{Sn}$ and $\mathrm{RE}$ atoms makes it difficult for them to form replacement atom- type solid solutions, so the RE atoms gather at defects, such as dendrite boundaries. Since the mechanical behavior of solder alloys depends on the microstructure, it is critically needed to conduct a systematic quantitative microstructure study at all relevant length scales [57]. RE element enhances the mechanical strength and creep rupture life of solder alloys like $\mathrm{Sn}-\mathrm{Ag}, \mathrm{Sn}-\mathrm{Cu}$ and SAC lead fee solder alloy because RE elements can promote chemical reactions at the interface and provide very strong bonding during soldering [14,58,75$76,80,82-85]$.

In the present study RE Lanthanum-La is selected for the investigation. The main objective of this paper is to study the effect of adding small amount of La on the microstructure and IMS formation of SAC-305 solder alloy with varying environmental conditions implemented during service. Lanthanum (La) is considered as the best doping element for SAC solder alloys due to their lower cost, wide availability and low melting point as compare to the other RE elements $[88,89]$. In steel industry Lanthanum is added to steel to improve its malleability, resistance to impact and ductility. Being surface active agents, even minor quantity of La significantly enhance the reliability of solder [90]. In addition the diameter of a La atom is $0.181 \mathrm{~nm}$, while that of $\mathrm{Sn}$ is $0.141 \mathrm{~nm}$ which is $28 \%$ smaller than that of La. Owning to this it is difficult for La atoms to substitute $\mathrm{Sn}$ atoms in the matrix. Consequently it is easy for $\mathrm{La}$ atoms to agglomerate at dendrite boundaries, and refine dendrite of the grains [67]. This may enhance the resistance to grain growth which may results in the refinement of the microstructure.

\section{Experimental Procedure}

The base material used in this study is SAC305 lead free solder alloy and the RE used is Lanthanum - La. Three levels of RE doping were used and the final alloy compositions in weight percent are shown in Table 1 below:

The 96.5Sn3.5Ag0.5Cu solder was obtained from Nathan Trotter \& Co. in the form of solder bar. Other $96.5 \mathrm{Sn} 3.5 \mathrm{Ag} 0.5 \mathrm{Cu}-\mathrm{La}$ alloys were obtained from Atlantic Metals \& Alloys Inc. also in the form of solder bar. Some of the samples were then aged isothermally in high temperature oven. Two levels of temperatures ranges were used for the thermal aging: $100^{\circ} \mathrm{C}$ and $180^{\circ} \mathrm{C}$. Similarly two levels 60 and 120 hours: were used as aging time factor. Including the case of no thermal aging condition (as-cast), there were 5 combinations of thermal treatment on the specimens and considering the four alloy compositions used in this study, there were $4 \times 5=20$ test conditions.

Samples were cross-sectioned and mounted in epoxy, then ground by different grit sized silicon carbide $(\mathrm{SiC})$ emery papers in a sequence of $320,600,800,1000$ and 1200 and subsequently mechanical polished with diamond paste $(6 \mu \mathrm{m}, 3 \mu \mathrm{m}$ and $1 \mu \mathrm{m})$ and $0.05-\mu \mathrm{m}$ alumina

\begin{tabular}{|l|r|r|r|r|}
\hline \multirow{2}{*}{ Solder Alloy } & \multicolumn{4}{|c|}{ Elemennt (wt\%) } \\
\cline { 2 - 6 } & Sn & Ag & \multicolumn{1}{|c|}{ Cu } & La \\
\hline SAC305 & 96.5 & 3 & 0.5 & 0 \\
\hline SAC305-0.05La & 96.45 & 3 & 0.5 & 0.1 \\
\hline SAC305-0.25La & 96.26 & 2.99 & 0.5 & 0.3 \\
\hline SAC305-0.5La & 96.02 & 2.99 & 0.5 & 0.5 \\
\hline
\end{tabular}

Table 1: Composition of selected solder alloys. suspension. Pressurized water coolant is applied during grinding process to prevent sample heating. Ultrasonic cleaning for 2 minutes was carried out after each step of diamond paste polishing to remove any diamond abrasive on the sample surface. Polishing with alumina suspension does not reveal the precipitates. To reveal the precipitates, the sample was again polished with alkaline $0.05 \mu \mathrm{m}$ silica suspension. The alkaline solution preferentially etches the Tin-Sn grains at a higher rate and therefore helps to clearly identify the Ag3Sn precipitates [91]. The samples were then etched for several seconds using etching solution of $93 \% \mathrm{CH}_{3} \mathrm{OH}+5 \% \mathrm{HNO}_{3}+2 \% \mathrm{HCl}$ as used by most of the researcher for SAC alloys $[12,14,67,88]$. Etching time is tabulated below Table 2 .

After thermal aging, microstructure of the polished samples was performed using optical microscope (Olympus GX51, Olympus Co. Japan) and Scanning Electron Microscope - SEM (JSM-5910, JEOL Japan) coupled to an Energy Dispersive X-ray Spectroscope -EDS (Oxfordins Inca-200). In order to hinder the charging of the epoxy mount, gold sputter coating was performed on the SEM sample with SPI Sputter coater JEE-420. Dispersion of different solder elements and the elemental analysis of IMC phases were performed using a JEOL JXA-733 superprobe electron probe microanalyzer equipped with Bruker AXS 4010 XFlash silicon drift energy dispersive X-ray (EDX) detector and QUANTX software. X-ray diffraction (XRD) measurements were carried out in order to determine the constitution of the phases forming the samples microstructure. XRD patterns were obtained utilizing a JDX-3532 (JEOL Japan) with a 2-theta range from $5^{\circ}$ to $80^{\circ}, \mathrm{Cu}-\mathrm{Ka}$ radiation with a wavelength, $\lambda$, of $0.15406 \mathrm{~nm}$.

\section{Results and Discussion}

\section{XRD analysis}

XRD analysis was conducted to identify the type of IMC phases. Figure 2 exhibits the resulting XRD patterns for as-cost SAC305 with no La doping and that SAC305 with $0.5 \mathrm{wt} \%$ La after thermal aging of 120 hours at $180^{\circ} \mathrm{C}$ of each sample. It was observed that the microstructure of un-doped SAC305 alloy contained two IMCs phases, i.e. $\mathrm{Ag}_{3} \mathrm{Sn}$ and $\mathrm{Cu}_{6} \mathrm{Sn}_{5}$ while that of lanthanum doped SAC305 alloy contained three IMC phases i.e. $\mathrm{Ag}_{3} \mathrm{Sn}, \mathrm{Cu}_{6} \mathrm{Sn}_{5}$ and $\mathrm{La}_{5} \mathrm{Sn}_{3}$. Previous studies $[25,57,61,86]$ found that Lanthanum doped SAC alloy will cause $\mathrm{LaSn}_{3}$ IMCs while our results shows the presence of $\mathrm{La}_{5} \mathrm{Sn}_{3}$ instead of $\mathrm{LaSn}_{3}$.

\section{Grain size}

To study the grain size of the solder material, optical microscopy with cross polarized light was used. With the help of cross polarized light, grains with different shade can be viewed under the microscope. Figure 3 shows the typical images of $96.5 \mathrm{Sn} 3 \mathrm{Ag} 0.5 \mathrm{Cu}$ and $96.5 \mathrm{Sn} 3 \mathrm{Ag} 0.5 \mathrm{Cu}-$ $0.5 \mathrm{La}$ after thermal aging of 120 hours at $180^{\circ} \mathrm{C}$ of each sample [92,93]. These Figures shows a significant decrease in grain size, due to the addition of lanthanum.

The grain size as a function of different La composition and aging temperature is plotted in Figures 4 and 5 respectively. The Figures illustrate that the grain size of lanthanum alloy is much smaller than un-doped SAC305 alloy. Also grain size decreases significantly up to $0.05 \%$ of La doping and then increase slightly with increasing amount of La doping. This is consistent with the previous studies conducted by Min et al. [25] and Sadiq et al. [94] for Sn-3.5Ag and SAC305 alloy respectively with similar La doping. Also a slight change in the grain size for La-doped alloy has been observed with thermal aging. This demonstrates that La-doping refines the grains which comply to 
Citation: Yasmin T, Sadiq M, Khan MI (2014) Effect of Lanthanum Doping on the Microstructure Evolution and Intermetallic Compound (IMC) Growth during Thermal Aging of SAC305 Solder Alloy. J Material Sci Eng 3: 141. doi:10.4172/2169-0022.1000141

\begin{tabular}{|l|c|}
\hline SAC Alloy & Etching Time (sec.) \\
\hline SAC305 & 10 \\
\hline SAC305-0.05La & 20 \\
\hline SAC305-0.25La & 40 \\
\hline SAC305-0.5La & 80 \\
\hline
\end{tabular}

Table 2: Etching time.

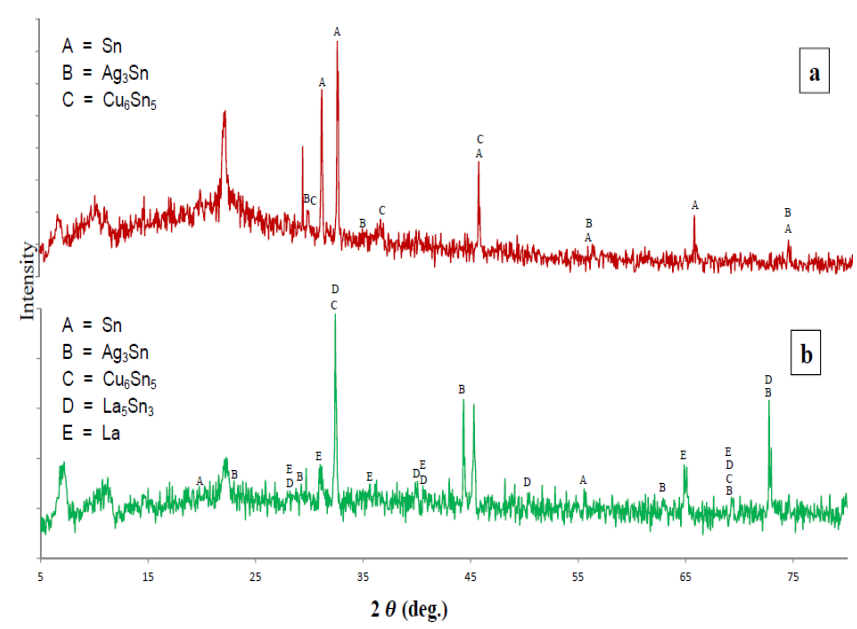

Figure 2: XRD profile of (a) SAC305 (b) SAC305 with 0.5La after thermal aging at $180^{\circ} \mathrm{C}$ for $120 \mathrm{hr}$.
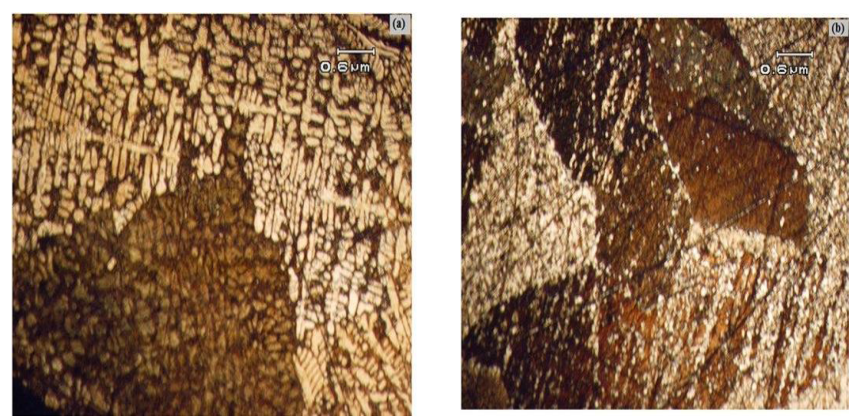

Figure 3: Optical microscopy (a) SAC305 (b) SAC305 with 0.5La after thermal aging at $180^{\circ} \mathrm{C}$ for $120 \mathrm{hr}$.

the work of Min et al. [25] and Sadiq et al. [94]. The philosophy of this refinement is because of the particular effect of La adsorption at different planes in the $\mathrm{Sn}-\mathrm{Ag}-\mathrm{Cu}$ alloys.

\section{Microstructure analysis}

The microstructure of the doped and un-doped SAC305 solder alloy was investigated in SEM and ordinary secondary electron microscopy images have been produced for each alloy composition. In the as-cast condition, the microstructure of SAC305 alloy comprises of dendritic $\beta$-Sn phase and Sn-Ag-Cu ternary eutectic network where intermetallic particles were finely distributed in the Sn matrix as shown in Figure 6. From the EDS and XRD analysis, the IMC found were mainly $\mathrm{Ag}_{3} \mathrm{Sn}$ and $\mathrm{Cu}_{6} \mathrm{Sn}_{5}$. There is very a clear boundary between dendritic $\beta$-Sn phase and $\mathrm{Sn}-\mathrm{Ag}-\mathrm{Cu}$ ternary eutectic regions. After thermal aging, the size of $\mathrm{Ag}_{3} \mathrm{Sn}$ and $\mathrm{Cu}_{6} \mathrm{Sn}_{5}$ particles in $\mathrm{Sn}-\mathrm{Ag}-\mathrm{Cu}$ eutectic network becomes bigger and more uniformly dispersed. The reason for increase in the particle size of $\mathrm{Cu}_{6} \mathrm{Sn}_{5}$ with thermal aging is the increase in the diffusion rate of $\mathrm{Cu}$ into $\mathrm{Sn}$ [92].
The "as cast" and "thermally aged" SEM micrographs for un-doped SAC-305 and SAC305 with 0.5wt\% La doped alloy are shown in Figure 7. After thermal aging coarsening of IMCs particles take place. It could be observed from the images that the microstructure of La-doped sample is more refine the un-doped sample. After thermal aging at $180^{\circ} \mathrm{C}$ the size of $\mathrm{Ag}_{3} \mathrm{Sn}$ and $\mathrm{Cu}_{6} \mathrm{Sn}_{5}$ particles in $\mathrm{SnAgCu}$ eutectic region increased and more uniformly dispersed. Owing to this dispersion it is difficult to identify the boundaries of $\beta$-Sn dendrite and eutectic region clearly.
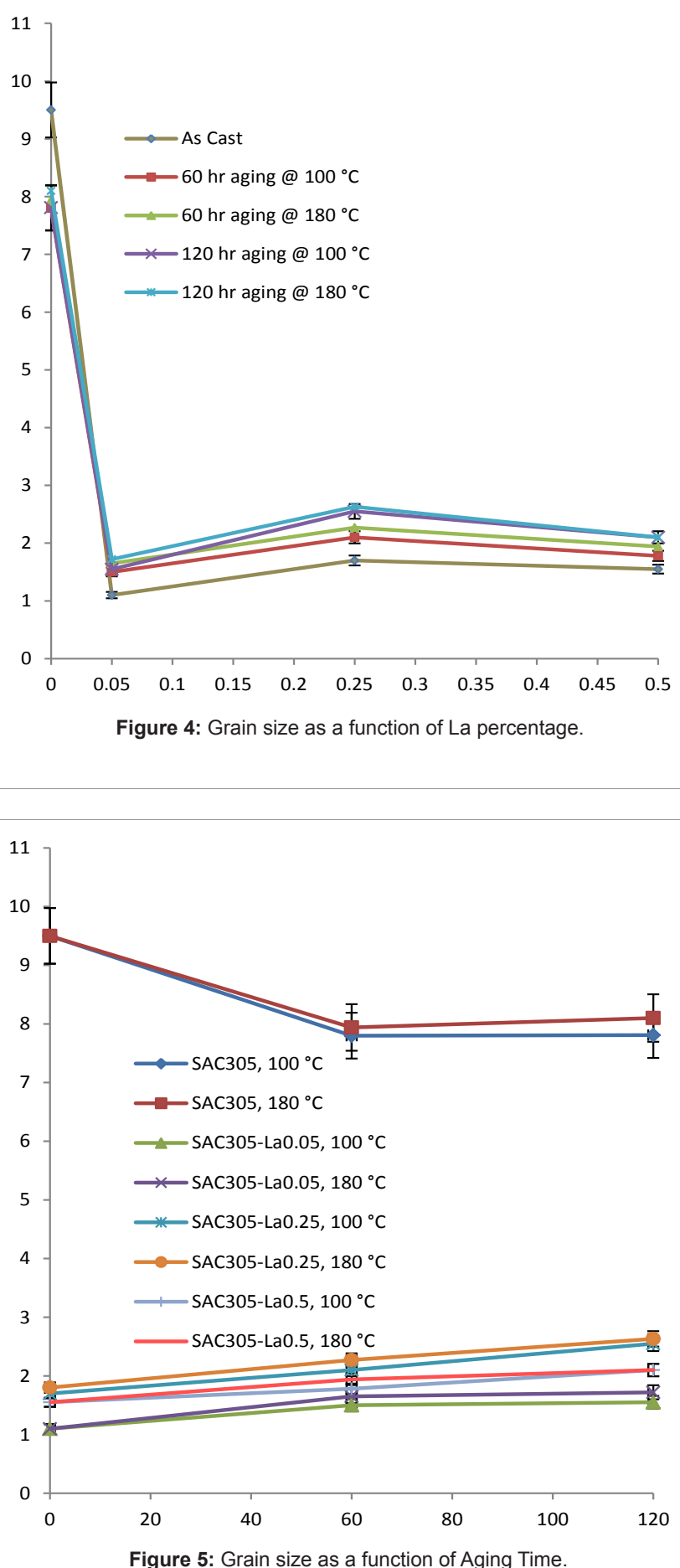

Figure 5: Grain size as a function of Aging Time. 
Citation: Yasmin T, Sadiq M, Khan MI (2014) Effect of Lanthanum Doping on the Microstructure Evolution and Intermetallic Compound (IMC) Growth during Thermal Aging of SAC305 Solder Alloy. J Material Sci Eng 3: 141. doi:10.4172/2169-0022.1000141

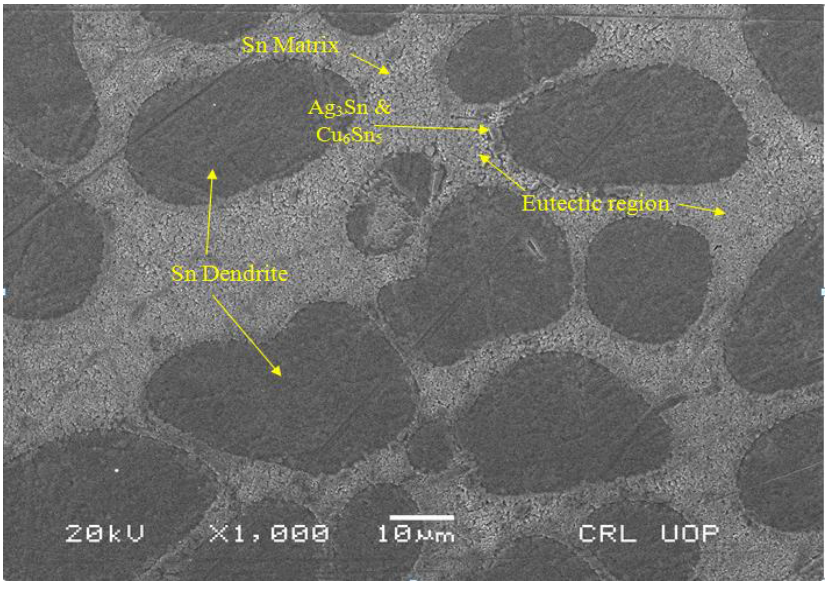

Figure 6: SEM image of as-cast un-doped SAC305.

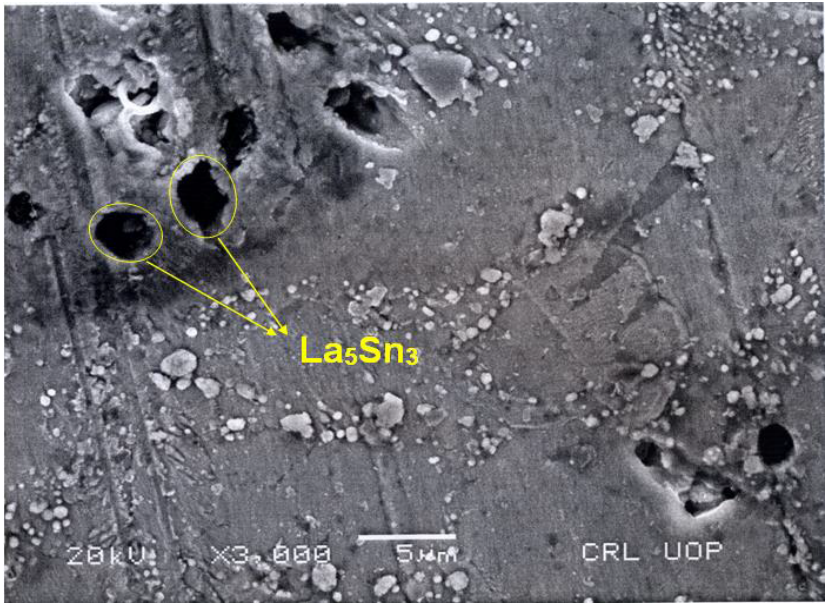

Figure 7: $\mathrm{A} \mathrm{La}_{5} \mathrm{Sn}_{3}$ cluster in SAC305-0.5La solder.
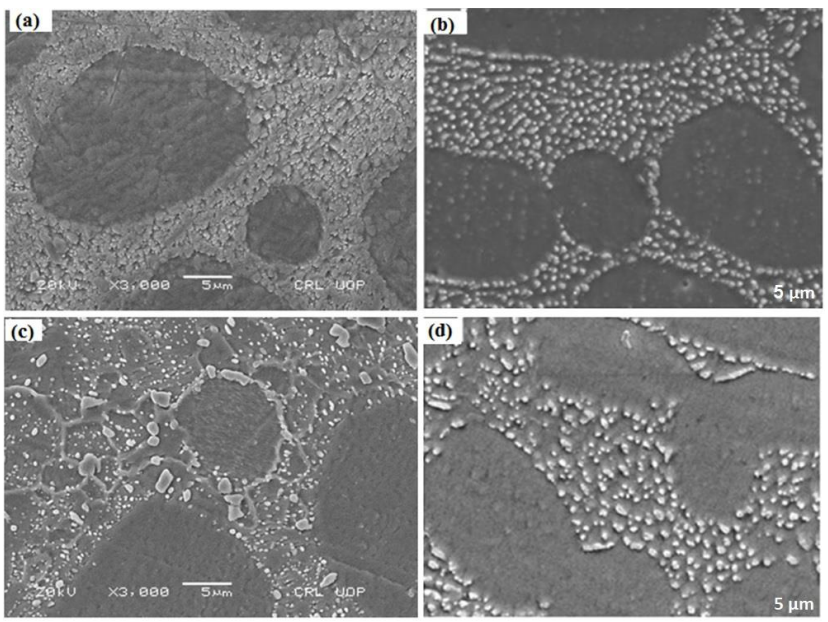

Figure 8: Micrographs of (a) as-cast SAC305 and (b) SAC305-La before thermal aging, and (c) SAC305 and (d) SAC305-0.5La after thermal aging.

The XRD and EDS tests found that the doping elements La exist in SAC305 solder alloy in two forms: as La element or as La5Sn3 IMC.
The La-Sn IMC has complex branch structure [89], which is usually look like clusters of snowflakes [57] in SEM images. With the help of EDX analysis very high amount of La concentration of observed in these snowflakes. Moreover It was also observed that quantity La5Sn3 IMC depend upon the concentration La doping i.e. with high $0.5 \mathrm{wt} \%$ of lanthanum bigger snowflakes has be observed as shown in Figure 8 while small isolated snow can be seen with less La doping which is consistent with the results of Min et al [25].

La doping greatly reduces the $\mathrm{Ag}_{3} \mathrm{Sn}$ and $\mathrm{Cu}_{6} \mathrm{Sn}_{5}$ particle size particle during thermal aging. Surface area averaged particle size of $\mathrm{Cu}_{6} \mathrm{Sn}_{5}$ particles was obtained as per ASM handbook [95]. The particle sizes for the full data set are plotted in Figure 9 as function of La doping level. It can be seen that La doping effectively suppresses the growth of $\mathrm{Ag}_{3} \mathrm{Sn}$ and $\mathrm{Cu}_{6} \mathrm{Sn}_{5}$ intermetallic particle.

The distribution of $\mathrm{Sn}, \mathrm{Ag}, \mathrm{Cu}$ and $\mathrm{La}$ was observed by using electron micro probe analysis (EPMA) coupled with X-ray spectroscopy (EDX). The elemental analyses map in Figure 10 demonstrates that elemental $\mathrm{La}$ is uniformly dispersed on the whole solder area which is consistent with Min et al. [25].

Under thermal aging conditions, evolution of IMC particles i.e. $\mathrm{AgSn}_{3}$ and Cu6Sn5 was observed. Owing to this $\mathrm{Cu}_{6} \mathrm{Sn}_{5}$ particle can be easily distinguished from $\mathrm{AgSn}_{3}$ particles as shown in Figure 11.

\section{Concluding Remarks}

Keeping in view the result and observations of this study several conclusions can be made.

1. In the as-cast condition, the microstructure of SAC305 alloy comprises of dendritic $\beta$-Sn phase and Sn-Ag-Cu ternary eutectic network where intermetallic particles were finely distributed in the Sn matrix.

2. Addition of lanthanum to Sac305 solder alloy significantly reduced the IMC particle size.

3. La doping effectively suppresses the growth of $\mathrm{Ag}_{3} \mathrm{Sn}$ and $\mathrm{Cu}_{6} \mathrm{Sn}_{5}$ intermetallic particle during thermal aging.

4. La doping significantly reduce the grain size and keep the grain size stable during thermal aging.

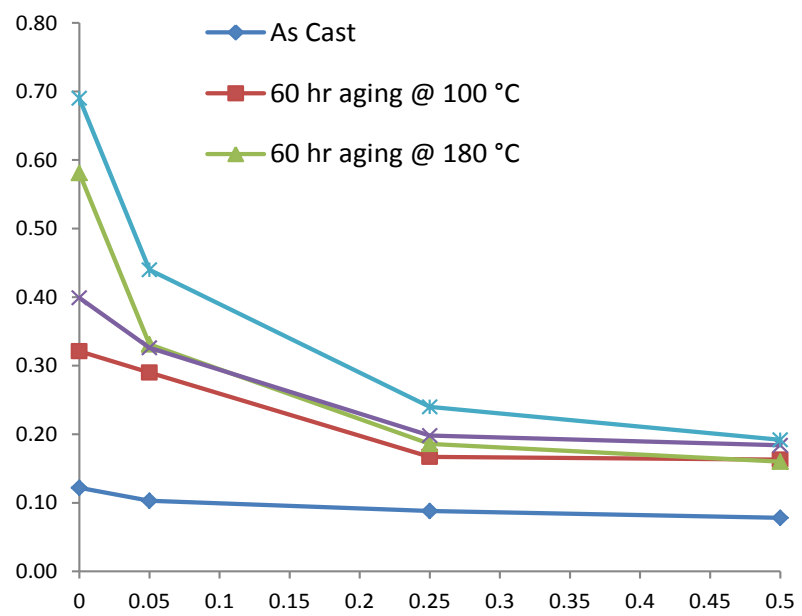

Figure 9: IMC Particle size as a function of La wt\%. 
Citation: Yasmin T, Sadiq M, Khan MI (2014) Effect of Lanthanum Doping on the Microstructure Evolution and Intermetallic Compound (IMC) Growth during Thermal Aging of SAC305 Solder Alloy. J Material Sci Eng 3: 141. doi:10.4172/2169-0022.1000141
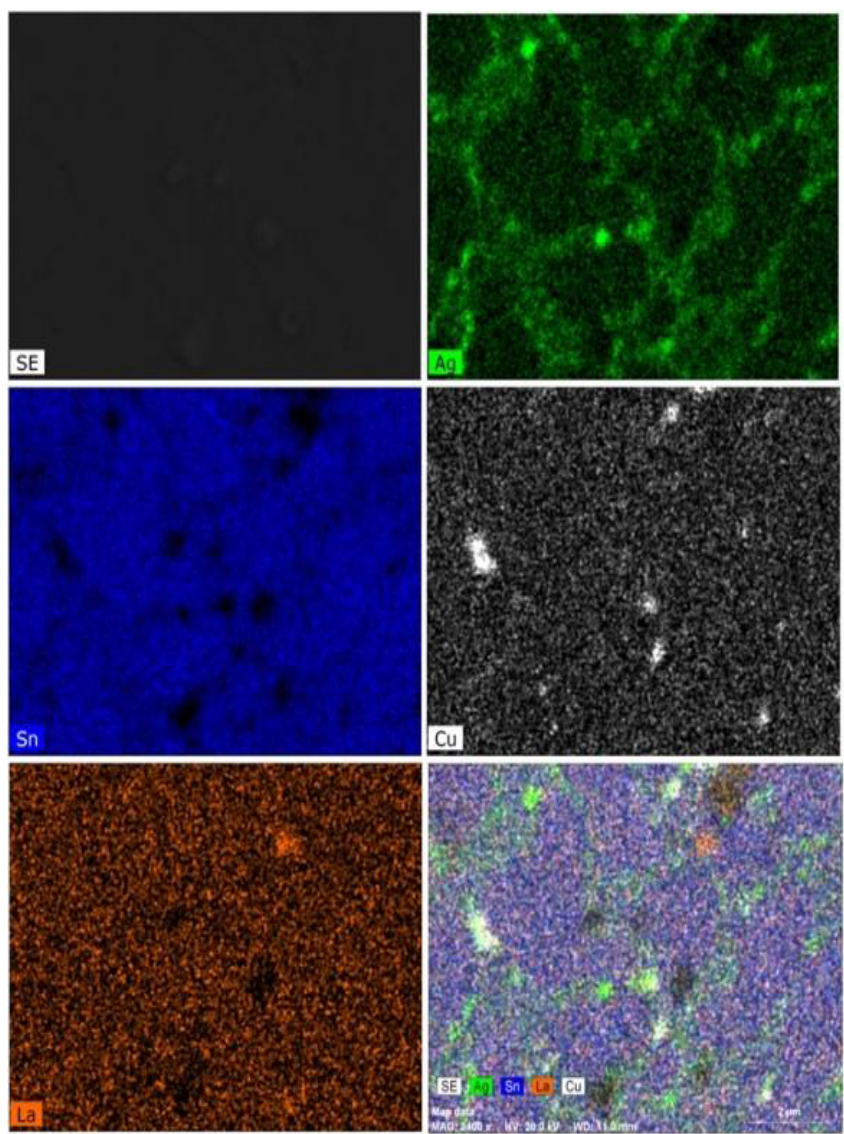

Figure 10: EMPA elemental mapping of SAC305-0.5La after $120 \mathrm{~h}$ aging at $100^{\circ} \mathrm{C}$.
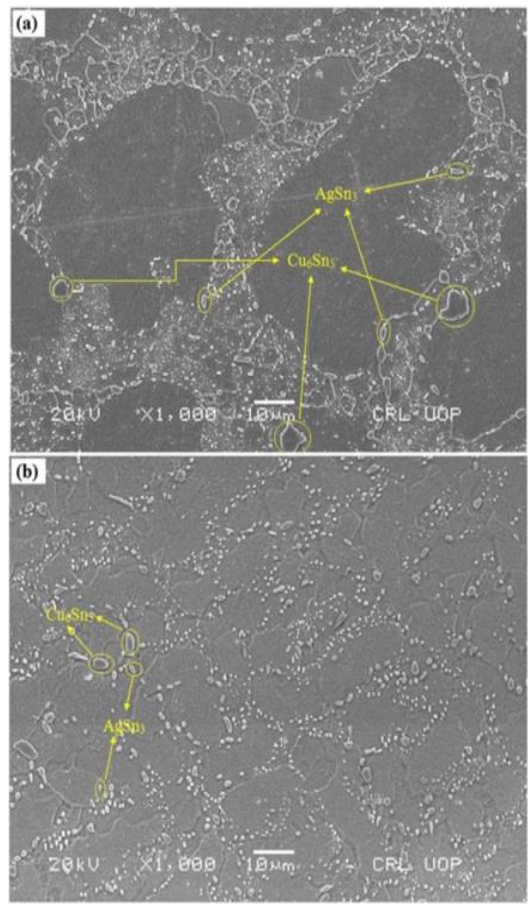

Figure 11: Particle and dendrite boundaries coarsening at aging (a) undoped SAC305 (b) La doped SAC305, after $60 \mathrm{~h}$ aging at $180^{\circ} \mathrm{C}$.
5. Addition of lanthanum with $0.5 \mathrm{wt} \%$ conduces to a new type of IMC, observed as $\mathrm{La}_{5} \mathrm{Sn}_{3}$.

\section{References}

1. Abtew M, Selvaduray G (2000) Lead-free Solders in Microelectronics Original Research Article Materials Science and Engineering: R: Reports 5: 95-141.

2. Muller WH (2004) Morphology changes in solder joints experimental evidence and physical understanding. Microelectronics Reliability 44: 1901-1914.

3. Shena J, Chana YC, Liub SY (2008) Growth mechanism of bulk $\mathrm{Ag}_{3} \mathrm{Sn}$ intermetallic compounds in Sn-Ag solder during solidification. Intermetallics 16 1142-1148.

4. Garcia LR, Osório WR, Peixoto LC, Garcia A (2009) Correlation between mechanical properties and dendrite array of the Sn-Zn alloy for lead-free solder. Materia- Rio de Janeiro 14: 767-776.

5. Garcia LR, Osório WR, Peixoto LC, Garcia A (2010) Mechanical properties of $\mathrm{Sn}-\mathrm{Zn}$ lead-free solder alloys based on the microstructure array. Materials Characterization - Mater Charact 61: 212-220.

6. Anil K (2012) Development of new lead-free solders for electronics industry, M,Sc Thesis, Middle East Technical University, Turkey.

7. IPC Roadmap, A guide for assembly of lead-free electronics (2000) IPC Northbrook, IL.

8. Ames Laboratory, Alternatives to Lead-Based Solders, 2013.

9. Lau J, Dauksher W, Smetana J (2003) HDPUG's Design for Lead-Free Solder Joint Reliability of High-Density Packages. IPC SMEMA Council APEX 42: 1-8.

10. Kim KS, Huh SH, Suganuma K (2003) Effects of intermetallic compounds on properties of $\mathrm{Sn}-\mathrm{Ag}-\mathrm{Cu}$ lead-free soldered joints. Journal of Alloys and Compounds 352: 226-236.

11. Yoon JW, Kim SW, Jung SB (2005) IMC morphology, interfacial reaction and joint reliability of $\mathrm{Pb}$-free $\mathrm{Sn}-\mathrm{Ag}-\mathrm{Cu}$ solder on electrolytic Ni BGA substrate. Journal of Alloys and Compounds 392: 247-252.

12. Yu DQ, Wang $L$ (2008) The growth and roughness evolution of intermetallic compounds of $\mathrm{Sn}-\mathrm{Ag}-\mathrm{Cu} / \mathrm{Cu}$ interface during soldering reaction. Journal of Alloys and Compounds 458: 542-547.

13. Farooq M, Ray S, Sarkhel A, Goldsmith C (2001) Evaluation of lead (Pb)-free ceramic ball grid array (CBGA): wettability, microstructure and reliability, 51st Electronic Components and Technology Conference, USA.

14. Wu CML, Yu DQ, Law CMT, Wang L (2004) Properties of lead-free solder alloys with rare earth element additions. Materials Science and Engineering 44: 1-44

15. Wang $\mathrm{CH}$, Chen SW (2006) Sn-0.7 wt. \%Cu/Ni interfacial reactions at $250^{\circ} \mathrm{C}$. Acta Materialia 54: 247-253.

16. Chan YC, Yang D (2010) Failure mechanisms of solder interconnects unde current stressing in advanced electronic package. Progress in Materials Science 55: 428-475.

17. Zeng K, Tu KN (2002) Six cases of reliability study of $\mathrm{Pb}$ free solder joints in electronic packaging technology. Materials Science and Engineering 38: 55-105.

18. Shang PJA, Liu ZQA, Pang XYA, Li DXA, Shang JK (2009) Growth mechanisms of Cu3Sn on polycrystalline and single crystalline Cu substrates. Acta Materialia 57: 4697-4706.

19. Laurila T, Vuorinen V, Kivilahti JK (2005) Interfacial reactions between leadfree solders and common base materials. Materials Science and Engineering R 49: 1-60.

20. Nai SML, Wei J, Gupta M (2009) Interfacial intermetallic growth and shea strength of lead-free composite solder joints. Journal of Alloys and Compounds 473: 100-106.

21. Frear DR (1996) The mechanical behavior of interconnect materials for electronic packaging. JOM 48: 49-53.

22. Yao D, Shang JK (1997) Effect of Load-Mix on Fatigue Crack Growth in 63Sn37Pb Solder Joints. Journal of Electronic Packaging 119: 114-118.

23. Pan J, Chou TC, Willie JBD, Toleno BJ (2009) Effects of reflow profile and thermal conditioning on intermetallic compound thickness for $\mathrm{SnAgCu}$ soldered joints. Soldering \& Surface Mount Technology 21: 32-37. 
Citation: Yasmin T, Sadiq M, Khan MI (2014) Effect of Lanthanum Doping on the Microstructure Evolution and Intermetallic Compound (IMC) Growth during Thermal Aging of SAC305 Solder Alloy. J Material Sci Eng 3: 141. doi:10.4172/2169-0022.1000141

Page 7 of 8

24. Li GY, Chen BL, Shi XQ, Wong SCK, Wang ZF (2006) Effect of Sb addition on tensile strength of Sn-3.5Ag-0.7Cu solder alloy joint. Thin Solid Films 504 421-425.

25. Pei M, Jianmin Q (2008) Effect of Lanthanum Doping on the Microstructure of Tin-Silver Solder Alloys. Journal of Electronic Materials 37: 331-338.

26. IVF Project Report 06/07 Review of the Impact of Intermetallic Layers on the Brittleness of Tin-Lead and Lead-Free Solder Joints.

27. Iting T, Li JT, Yen SF, Chuang TH, Ku LR, et al. (2005) Identification of Mechanical Properties of Intermetallic Compounds on Lead Free Solder. Proceedings of the 55th Electronic Components and Technology Conference: 687-691.

28. Fields RJ, Low SR (1991) Physical and Mechanical Properties of Intermetallic Compounds Commonly Found in Solder Joints.

29. Hare E (2013) Intermetallics in Solder Joints.

30. Ganesan S, Pecht M (2006) Lead-free electronics, John Wiley and Sons, Hoboken, NJ.

31. Choubey A, Yu H, Osterman M, Pecht M, Yun F, et al. (2008) Intermetallics characterization of lead-free solder joints under aging. Journal of Electronic Materials 37: 1130-1138.

32. McCluskey P, Grzybowski R, Podlesak T (1996) High temperature electronics, CRC Press.

33. Parmentier B, Vermesan O, Beneteau L (2003) Design of high temperature electronics for well logging applications. International Conference on High Temperature Electronics HITEN, Oxford

34. Luhua X, Pang JHL, Che FX (2005) Intermetallic Growth and Failure Study for Sn-Ag-Cu/ENIG PBGA Solder Joints Subject to Thermal Cycling. 55th Proceedings, Electronic Components and Technology Conference, Lake Buena Vista, FL.

35. Anderson IE, Harringa JL (2004) Elevated temperature aging of solder joints based on Sn-Ag-Cu: effects on joint microstructure and shear strength. Journal of Electronic Materials 33: 1485-1496.

36. Rönkä KJ, vanLoo FJJ, Kivilahti JK (1998) A diffusion-kinetic model for predicting solder/conductor interactions in high density interconnections. Metallurgical and Materials Transactions A 29: 2951-2956.

37. Tegehall P (2007) Review of the Impact of Intermetallic Layers on the Brittleness of Tin-Lead and Lead-Free Solder Joints. IVF Project Report 06/07.

38. El-Daly AA, Hammada AE, Fawzy Ab, Nasrallh DA (2013) Microstructure, mechanical properties, and deformation behavior of $\mathrm{Sn}-1.0 \mathrm{Ag}-0.5 \mathrm{Cu}$ solder after $\mathrm{Ni}$ and $\mathrm{Sb}$ additions. Materials and Design 43: 40-49.

39. Harris PG, Chaggar KS (1998) The Role of Intermetallic Compounds in Leadfree Soldering. Soldering \& Surface Mount Technology 10: 38-52.

40. Pratt RE, Stromswold El, Quesnel DJ (1996) Effect of Solid-State Intermetallic Growth on the Fracture Toughness of Cu/63Sn-37Pb Solder Joints. IEEE Trans. on Components, Packaging, and Manufacturing Technology - Part A, 19: $134-141$

41. Roubaud P, Ng G, Henshall G, Bulwith R, Herbet R, et al. (2001) Impact of Intermetallic Growth on the Mechanical Strength of Pb-Free BGA Assemblies. Proc. of the APEX Conf in San Diego, CA.

42. Tu KN, Thompson RD (1982) Kinetics of Interfacial Reaction in Bimetallic CuSn Thin Films. Acta Metallurgica 30: 947-952.

43. Mei Z, Ahmad M, Hu M, Ramakrishna G (2005) Kirkendall Voids at Cu/Solder Interface and Their Effects on Solder Joint Reliability. Proc. of the Electronic Components and Technology Conference, IEEE.

44. Borgersen P, Henderson DW (2013) Fragility of Pb-free Solder Joints; Universal Instruments, White paper.

45. Chiu TC, Zeng K, Stierman RD, Edwards, Ano K (2004) Effect of Thermal Aging on Board Level Drop Reliability for Pb-free BGA Packages. Proc. of the 54th Electronic Components and Technology Conference.

46. Anderson IE, Harringa JL (2004) Elevated Temperature Aging of Solder Joints Based on Sn-Ag-Cu: Effects on Joint Microstructure and Shear Strength. J of Electronic Materials 33: 1485-1496.

47. Law CMT, Wu CML, Yu DQ, Li M (2003) Solderability and growth of intermetallic compounds upon aging of Sn-Ag-RE and Sn-Cu-RE lead-free alloys. Presented at Conference of Material Science \& Technology, Chicago.

48. Mookam N, Kanlayasiri K (2011) Effect of soldering condition on formation of intermetallic phases developed between Sn-0.3Ag-0.7Cu low-silver lead-free solder and Cu substrate. Journal of Alloys and Compounds, 509: 6276-6279.

49. Kang SK (2003) Controlling $\mathrm{Ag}_{3} \mathrm{Sn}$ plate formation in near-ternary-eutectic Sn$\mathrm{Ag}-\mathrm{Cu}$ solder by minor $\mathrm{Zn}$ alloying. JOM 55: 34-38.

50. Kang SK (2005) Microstructure and mechanical properties of lead-free solders and solder joints used in microelectronic applications. IBM Journal of Research and Development 49: 607-620.

51. Kim KS, Huh SH, Suganuma K (2002) Effects of Cooling Speed on Microstructure and Tensile Properties of Sn-Ag-Cu Alloys, Materials Science and Engineering A 333: 106-114.

52. Frear DR, Jang JW, Lin JK, Zhang C (2001) Pb-Free Solders for Flip Chip Interconnects. JOM 53: 28-33.

53. Song JM, Lin JJ, Huang CF, Chuang HY (2007) Crystallization, morphology and distribution of $\mathrm{Ag}_{3} \mathrm{Sn}$ in $\mathrm{Sn}-\mathrm{Ag}-\mathrm{Cu}$ alloys and their influence on the vibration fracture properties. Materials Science and Engineering A, 466: 9-17.

54. Sims CT, Stoloff NS, Hagel WC (1987) Superalloys II. JohnWiley \& Sons, New York, NY, USA

55. Reid M, Pomeroy MJ, Robinson JS (2004) Microstructural instability in coated single crystal superalloys. Journal of Materials Processing Technology 153-154.

56. Lee LM, Mohammad AA (2013) Interfacial Reaction of Sn-Ag-Cu Lead-Free Solder Alloy on Cu: A Review. Advances in Materials Science and Engineering

57. Chen ZG, Shi YW, Xia ZD, Yan YF (2002) Study on the microstructure of a novel lead-free solder alloy Sn-Ag-Cu-RE and its soldered joints. Journal of Electronic Materials 31: 1122-1128.

58. Yaowu S, Tian J, Hao H, Zhidong X, Yongping L, et al. (2008) Effects of small amount addition of rare earth $\mathrm{Er}$ on microstructure and property of $\mathrm{SnAgCu}$ solder. Journal of Alloys and Compounds 453: 180-184.

59. Gao L, Xue S, Zhang L, Sheng Z, Ji F, et al. (2010) Effect of alloying elements on the properties and microstructure of $\mathrm{SnAgCu}$ solders. Microelectronic Engineering 87: 2025-2034

60. Liang L, Wang Q, Zhao Z (2007) Effect of Cerium addition on board leve reliability of $\mathrm{Sn}-\mathrm{Ag}-\mathrm{Cu}$ solder joint. 8th International Conference on Electronic Packaging Technology, Shanghai, China.

61. Chen Z, Shi Y, Xia Z, Yan y (2003) Properties of lead-free solder Sn-Ag-Cu containing minute amounts of rare earth. Journal of Electronic Materials 32 235-243.

62. Chen Z, Shi Y, Xia Z (2004) Constitutive relations on creep for Sn-Ag-Cu-RE lead-free solder joints. Journal of Electronic Materials 33: 964-971.

63. Li B, Shi Y, Lei Y, Guo F, Xia Z, et al. (2005) Effect of rare earth element addition on the microstructure of Sn-Ag-Cu solder joint. Journal of Electronic Materials 34: $217-224$

64. Hao H, Tian J, Shi YW, Lei YP, Xia ZD (2007) Properties of Sn3.8Ag0.7Cu Solder Alloy with Trace Rare Earth Element Y Additions. Journal of Electronic Materials 36: 766-774.

65. Wu CML, Wong YW (2007) Rare-earth additions to lead-free electronic solders Journal of Materials Science: Materials in Electronics 18: 77-91.

66. Dong W, Shi Y, Xia Z, Lei Y, Guo F (2008) Effects of Trace Amounts of Rare Earth Additions on Microstructure and Properties of Sn-Bi-Based Solder Alloy. Journal of Electronic Materials 37: 982-991.

67. Yu DQ, Zhao J, Wang L (2004) Improvement on the microstructure stability, mechanical and wetting properties of $\mathrm{Sn}-\mathrm{Ag}$-Cu lead-free solder with the addition of rare earth elements. Journal of Alloys and Compounds 376: 170-175.

68. Gao L, Xue S, Zhang L, Sheng Z, Jia F, et al. (2010) Effect of alloying elements on properties and microstructures of $\mathrm{SnAgCu}$ solders. Microelectronic Engineering 87: 2025-2034.

69. Zhang L, Xue SB, Gao LL, Dai W, Feng Ji, et al. (2011) Microstructure characterization of $\mathrm{SnAgCu}$ solder bearing $\mathrm{Ce}$ for electronic packaging Microelectronic Engineering 88: 2848-2851.

70. Hui L (2013) Effects of Small Amount Addition of Rare Earth Y on Microstructure and Property of Sn3.0Ag0.5Cu Solder. Key Engineering Material 584: 3-8. 
Citation: Yasmin T, Sadiq M, Khan MI (2014) Effect of Lanthanum Doping on the Microstructure Evolution and Intermetallic Compound (IMC) Growth during Thermal Aging of SAC305 Solder Alloy. J Material Sci Eng 3: 141. doi:10.4172/2169-0022.1000141

Page 8 of 8

71. Chen W, Kong J, Chen WJ (2011) Effect of rare earth Ce on the microstructure, physical properties and thermal stability of a new lead-free solder. Journal of Mining and Metallurgy B: Metallurgy 47: 11-21.

72. Guo F, Zhao M, Xia Z, Lei Y, Li X, et al. Lead-free solders with rare earth additions. JOM 61: 39-44.

73. Wang L, Yu DQ, Zhao J, Huang ML (2002) Improvement of wettability and tensile property in Sn-Ag-RE lead-free solder alloy. Materials Letters 56: 10391042

74. Ma X, Qian Y, Yoshida F (2002) Effect of La on the Cu-Sn intermetallic compound (IMC) growth and solder joint reliability. Journal of Alloys and Compounds 334: 224-227.

75. Wu CML, Yu DQ, Law CMT, Wang L (2002) The properties of Sn-9Zn leadfree solder alloys doped with trace rare earth elements. Journal of Electronic Materials 31: 921-927.

76. Wu CML, Yu DQ, Law CMT, Wang L (2002) Microstructure and mechanical properties of new lead-free Sn-Cu-RE solder alloys. Journal of Electronic Materials 31: 928-932.

77. Zhu Y, Fang H, Qian Y (1993) A Study of Sn-Pb-Re Solder. MRS Proceedings, Electronic Packaging Materials Science.

78. Dimová KP, Trnková LR, Ožvold M, Turňa M (2011) Influence of Ce on growth of IMC during aging at the interface of lead-free solder and cu substrate, Metal.

79. Zeng G, Xue S, Zhang L, Gao L, Lai Z, et al. (2011) Properties and microstructure of $\mathrm{Sn}-0.7 \mathrm{Cu}-0.05 \mathrm{Ni}$ solder bearing rare earth element Pr. Journal of Materials Science: Materials in Electronics 22: 1101-1108.

80. Zhang L, Cui J, Han J, Guo Y, He C (2012) Microstructures and properties of SnZn-xEr lead-free solders. Journal of Rare Earths 30: 790-793.

81. Wu CML, Yu DQ, Law CMT, Wang L (2002) Improvements of microstructure wettability, tensile and creep strength of eutectic Sn-Ag alloy by doping with rare earth elements. Journal of Material Research 31: 3146-3154.

82. Sun Y, Xue F, Zhou J (2005) Lead-free solders based on the Sn-8Zn-3Bi ternary alloy with additions of In, $\mathrm{Nd}$ or La. 6th International Conference on Electronics Packaging Technology, Dameisha, Shenzhen, China

83. Zeng G, Xue S, Zhang L, Gao L, Lai Z, et al. (2011) Properties and microstructure of $\mathrm{Sn}-0.7 \mathrm{Cu}-0.05 \mathrm{Ni}$ solder bearing rare earth element $\mathrm{Pr}$. Journal of Materials Science: Materials in Electronics 22: 1101-1108.

84. Zhou J, Sun Y, Xue F (2005) Properties of low melting point Sn-Zn-Bi solders Journal of Alloys and Compounds 397: 260-264.

85. Wu CML, Law CMT, Yu DQ, Wang L (2003) The wettability and microstructure of Sn-Zn-RE alloys. Journal of Electronic Material 32: 63-69.

86. Xia ZD, Chen ZG, Shi TW, Mu N, Sun N (2002) Effect of rare earth element additions on the microstructure and mechanical properties of tin-silver-bismuth solder. Journal of Electronic Material 31: 564-567.

87. Xia ZD, Chen ZG, Shi YW, Mu N, Sun N (2002) Study on the microstructure of a novel lead-free solder alloy SnAgCu-RE and its soldered joints. Journal of Electronic Material 31: 1122-1128.

88. Zhao XY, Zhao MQ, Cui XQ, Tong MX (2007) Effect of Cerium on microstructure and mechanical properties of $\mathrm{Sn}-\mathrm{Ag}-\mathrm{Cu}$ system lead-free solder alloys. Transactions of Nonferrous Metals Society of China 17: 805-810.

89. Dudek M, Sidhu R, Chawla N (2006) Novel rare-earth-containing lead-free solders with enhanced ductility. JOM 58: 57-62.

90. Ma X, Qian Y, Yoshida F (2002) Effect of La on the Cu-Sn intermetallic compound (IMC) growth and solder joint reliability. Journal of alloys and compounds 334: 224-227.

91. Tunga KR (2008) Study of Sn-Ag-Cu alloy reliability through materia microstructure evolution and laser moire interferometry. PhD Thesis, Georgia Institute of Technology, USA.

92. Shazlin SO, Nurulakmal MS (2001) Evaluation of Alloying Additions on the Microstructure and IMC Formation of $\mathrm{Sn}-\mathrm{Ag}-\mathrm{Cu}$ Solder on $\mathrm{Cu}$ and $\mathrm{Ni}(\mathrm{P})$ Substrates. World Academy of Science, Engineering and Technology 60: 405-410.

93. Allen SL, Notis MR, Chromik RR, Vinci RP (2004) Microstructural evolution in lead-free solder alloys: Part I. Cast Sn-Ag-Cu eutectic. Journal of materials research 19: 1417-1424.

94. Sadiq M, Pesci RL, Cherkaoui M (2013) Impact of Thermal Aging on the Microstructure Evolution and Mechanical Properties of Lanthanum-Doped TinSilver-Copper Lead-Free Solders. Journal of Electronic Materials 42: 492-501.

95. Voort V GF (2004) ASM Handbook. Metallography and Microstructures. 